\title{
A Theory of Urban Squatting and Land-Tenure Formalization in Developing Countries
}

\author{
by \\ Jan K. Brueckner \\ Department of Economics \\ University of California, Irvine \\ 3151 Social Science Plaza \\ Irvine, CA 92697 \\ e-mail: jkbrueck@uci.edu \\ and \\ Harris Selod \\ Paris School of Economics (INRA), CREST and CEPR \\ 48, boulevard Jourdan \\ 75014 Paris, France \\ e-mail: selod@ens.fr
}

January 2008

\begin{abstract}
This paper offers a new theoretical approach to urban squatting, reflecting the view that squatters and formal residents compete for land within a city. The key implication of this view is that squatters "squeeze" the formal market, raising the price paid by formal residents. The squatter organizer, however, ensures that this squeezing is not too severe, since otherwise the formal price will rise to a level that invites eviction by landowners (defensive expenditures by squatter households also help to forestall eviction). Because eviction is thus absent in equilibrium, the model differs crucially from previous analytical frameworks, where eviction occurs with some probability.
\end{abstract}




\title{
A Theory of Urban Squatting and Land-Tenure Formalization in Developing Countries
}

by

\author{
Jan K. Brueckner and Harris Selod*
}

\section{Introduction}

Informality of land tenure is usually a key characteristic of urban slums in the cities of developing countries. Informal tenure often involves squatting, where households occupy a parcel of land that belongs to someone else while paying no financial compensation. Given that 940 million people - over $30 \%$ of the world urban population - are estimated to live in slums (UN-Habitat, 2003), it is reasonable to think that several hundred million people worldwide live under informal land tenure, and that many of them are squatters. Although there are no consolidated figures on the extent of squatting, case studies often point to significant numbers. In the city of Dhaka, Bangladesh, for instance, squatter settlements are estimated to provide as much as $15 \%$ of the housing stock (World Bank, 2007).

While much anecdotal evidence about the daily lives of squatters and the organization of squatter settlements has accumulated (see Neuwirth, 2004, or Davis, 2006, for recent popular references), a few general observations can also be made. First, squatting is always associated with crowding, yielding very high population densities. Second, squatted land is usually not developed or serviced, leading to highly restricted and congested access to basic services for squatters. Third, while squatting is often thought to occur on vacant public land, much squatting also occurs on private property (see Buckley and Kalarickal, 2006, World Bank, 2007, Galiani and Schargrodsky, 2004, and Di Tella, et al. 2007). The vacant private land that attracts squatters may be vacant for several reasons, including speculative land-holding when disorganized financial markets constrain other opportunities for investment, or because of regulatory requirements or rent controls that make investing on that land unprofitable (Jimenez, 1984). Finally, although squatters do not pay formal rent to an owner, they incur costs associated with squatting, including possible payments made to a community "leader" 
(Lanjouw and Levy, 2002, World Bank, 2007).

Aside from these general tendencies, not much is known concerning the economic mechanisms that lead to the emergence and sustainability of squatting. The scope and persistence of squatting thus remain puzzling issues. Suggested explanations usually point to some external constraints or market imperfections as causes of squatting. For some authors, the main culprit is the unresponsiveness of housing supply, reflecting a variety of obstacles that include underinvestment in infrastructure, monopolies that control the availability of land (World Bank, 1993), topographical constraints, or mismanagement of public land development (World Bank, 2007). More provocatively, other observers stress the possible unwillingness of the private sector to respond to the low end of the market, which leaves the poor with no other options aside from informal housing. Others blame the existence of land-use interventions such as zoning that artificially increase the cost of formal housing and thus act as an invitation to squatting (Duranton, 2007). Discrimination in land and housing markets may also bar a significant fraction of the population, who are often migrants of rural origin, from entry into the formal market. Lastly, local governments may be unable to enforce the property rights of owners, or they may simply tolerate squatting, either because evictions are too politically costly or because of a desire to ensure some degree of tenure security for squatters. This latter view matches a remark in a World Bank report, which states that "most governments, unwilling to engage in mass evictions, have gradually condoned existing squatter housing while attempting to resist further squatting" (World Bank, 1993).

Even though these ideas are potentially useful, a formal theory of squatting can provide deeper insight into this important phenomenon. The purpose of the present paper is to offer such a theory, building on a small existing theoretical literature. The paper aims to provide a conceptual framework for analyzing some key issues related to squatting: How does squatting come into existence? How is the extent of squatting in a particular city determined? How do squatters interact with the formal housing market? What is the link between squatting and the prices of formal housing and land? How do policies targeted at squatters affect formal dwellers? The paper is based on the view that formal tenure and squatting represent two interlinked land uses within a single market and should be modeled as such. The model portrays squatters as 
"squeezing" the formal market by occupying land that could be developed for formal use. While this squeezing raises the formal price, too much price escalation invites eviction, and squatter communities are organized taking this threat into account.

In the small previous literature on the economics of squatting, some papers focus on the impact of eviction uncertainty on squatter behavior (their investment in housing capital), while others focus on landowner eviction decisions. An early contribution by Jimenez (1985) belongs to the first category. In the formal sector of his model, households must pay an exogenous rent, while squatters avoid a rental payment but incur other costs. These costs include an occupancy cost, which depends on the total squatter population, an outlay for "defensive" expenditures meant to protect the squatter's land, and a cost arising from possible loss of the housing investment in the event of eviction. The equilibrium requires households to be indifferent between formal tenure and squatting. The government evicts a fraction of squatter households, with this fraction matching the eviction probability that squatters use in computing their expected loss. Eviction costs per household rise with defensive expenditures and the number of squatters, and total costs must be covered by a fixed eviction budget. The equilibrium determines an eviction probability (fraction evicted) and an overall size for the squatter population. Jimenez carries out comparative-static analysis with his model, while also investigating the impact of squatter coalitions.

The present analysis adopts aspects of Jimenez's approach while introducing some key differences. Following Jimenez, defensive expenditures play a key role in the model, and eviction costs are also increasing in the size of the squatter population. However, in contrast to Jimenez's model, where the formal housing price is a parameter with no important role in the analysis, the formal price in the present model is endogenous and determined by the squeezing mechanism described above. Moreover, although the threat of eviction is present, actual evictions never occur, unlike in Jimenez's model. The reason is that the squatter "organizer," who governs the squatter group, sets the squatter population size, individual land consumption, and level of defensive expenditures to insure that the cost of eviction is high enough relative to the landowner's gain (which depends on the formal price) to make eviction unattractive. The organizer's goal is to maximize squatter utility subject to this "no-eviction" 
constraint. ${ }^{1}$ The model is thus a general equilibrium framework where squatters and formal households compete for the same land, with squatter decisions crafted so as not to invite eviction.

Since a model should be realistic to be useful, some evaluation of the realism of three key elements in the present framework is needed. First, although squatter evictions occur in reality, the fact that their volume is small relative to the large stock of squatter households justifies a model where evictions are absent in equilibrium (see Flood (2006) for eviction figures for several cities). Second, although squatting often occurs on public land not eligible for private development, squatting on private land is common enough (as explained above) to validate a model where squatters squeeze the formal market. Third, the presence in the model of a squatter organizer with substantial power to control the behavior of his group matches some real-world evidence. Examples of such organizers are common, including community bosses in Ecuador, shack lords in South Africa, or Mastaans in Bangladesh. A recent World Bank study on Dhaka (World Bank, 2007) noted that Mastaans "are self appointed leaders who set up committees, maintain links and have patronage from local and national political leaders, government officials and local law enforcing agencies." In line with the model's assumptions, Mangin (1967) noticed some forty years ago that associations in the squatter settlements of Peru "do seem to be able to control, to a certain extent, who will be members of the invasion group and the new residents." Organizers of land invasions also often collect payments from squatters in return for "ownership" of their plot, matching the defensive expenditures that play a key role in the model.

In addition to providing a new picture of the mechanisms underlying squatting, the paper's conceptual framework allows investigation of the general equilibrium effects of "formalization" policies, which require squatters to become formal residents, paying rent for the land they occupy. $^{2}$ The resulting analysis offers a new perspective given that the literature previously focused on various effects of formalization (improvement in tenure security, labor-market participation, access to credit, and health outcomes) but remained silent about impacts in the land market. Since opponents of sweeping formalization programs have noted that squatters may lose when faced with the full market prices for housing, such impacts are important. The 
model illuminates this issue, exposing squatter losses from formalization and showing that the gains of existing formal residents are sufficient to compensate them. The analysis thus points to a Pareto-improving way of escaping a city's squatter equilibrium.

Before proceeding to the analysis, the other contributions to the earlier squatting literature require some comment. Empirical work by Jimenez (1984) and Friedman, Jimenez and Mayo (1988) explores the effect of tenure insecurity on the price of informal housing. The results show that tenure security is valued, which provides one justification for formalization policies. Two other theoretical papers differ from Jimenez (1985) by endogenizing the eviction decision, as noted above. Rather than determining the volume of evictions via a fixed eviction-cost budget (as does Jimenez), landowners in Turnbull (2004) compare the formal price to the cost of eviction, as in the present model. Turnbull's formal price is exogenous (squeezing is absent), but since it is stochastic, evictions are generated with some probability. Hoy and Jimenez (1991) analyze a model with a similar structure.

The remainder of the paper is organized as follows. Section 2 presents the analysis of the basic model, including the analysis of formalization policies. Section 3 makes a key modification to the model by assuming that, although the squatter organizer can dictate the choices of his group, he cannot control the size of the squatter population, which is determined by free migration. Section 4 offers conclusions.

\section{Basic Model}

\subsection{The setup}

The analysis relies on a stylized model of a city containing both squatters and residents of formal housing. The first assumption is that the city's land area is fixed at $\bar{L}$. A variable land area could be introduced by making the model explicitly spatial, relying on a monocentric framework with commuting to a central workplace, or by assuming that the city faces an upward-sloping supply curve of land while suppressing any explicit spatial structure. Given that the main message of the analysis is independent of any particular assumptions on land supply, the fixed-land-area assumption is adopted for its simplicity. In addition, land is assumed to be homogeneous, so that differential job access is ignored. Another potentially important 
aspect of land heterogeneity is also suppressed at the outset of the analysis: infrastructure provision, or "servicing" of the land (public utilities, streets, etc.). Formal areas are typically serviced, while squatter areas are not, and the effect of this difference is considered once the basic analysis is complete.

Letting $L_{s}$ and $L_{f}$ denote the land occupied by squatters and residents of formal housing, respectively, the requirement that the available urban land is fully occupied can be written

$$
L_{s}+L_{f}=\bar{L}
$$

Overall land consumption by the two resident groups depends on their individual land consumption levels, which are in turn tied to consumption of housing. For simplicity, housing and land consumption are equated, with the structure component of housing suppressed. Therefore, housing consumption for a squatter household is equal to its consumption of land, denoted $q_{s}$, with $q_{f}$ denoting land (housing) consumption by a formal household. Introduction of housing capital would add inessential complexity to the model, with no change in its substance.

Letting $N_{s}$ denote the number of squatter households, the squatter land area must satisfy

$$
N_{s} q_{s}=L_{s}
$$

While $N_{s}$ is an endogenous variable in the model, the size of the city's formal population is fixed, with its value denoted $\bar{N}_{f}$. Even though both population sizes would be endogenous in a richer model, this assumption allows the analysis to focus on the impact of squatter migration into a city with an established formal population. The formal land area must then satisfy

$$
\bar{N}_{f} q_{f}=L_{f}
$$

The incomes of squatters and formal households are denoted $y_{s}$ and $y_{f}$, respectively. Given that squatters may be more likely than formal residents to hold inferior jobs or to be unemployed, $y_{s} \leq y_{f}$ is assumed to hold, with equality corresponding to the case where job quality 
for the two groups is equal. The main difference between squatters and formal households lies, of course, in their relations with the city's landowners, who are assumed to be absentee. ${ }^{3}$ While a squatter household occupies the land for free, a formal household pays rent to the owner of the land it occupies, with $p_{f}$ denoting the rent per unit of formal land. As a result, the individual consumption level $q_{f}$ is connected to $p_{f}$ via the household's housing demand function $d_{f}(\cdot)$, satisfying the relationship

$$
q_{f}=d_{f}\left(p_{f}\right) .
$$

With their land being occupied for free, land consumption by individual squatters is not governed by a demand function in the usual way. The level of $q_{s}$ is instead determined in an entirely differently fashion, which constitutes the main innovation of the paper. To begin the discussion, recall that squatters use a portion of their income for "defensive" expenditures, which are designed to raise the cost of eviction by landlords. These expenditures could consist of bribes paid to politicians, designed to undercut government support for eviction. Alternatively, the expenditures could cover the cost of legitimate political organizing, or perhaps payments to neighborhood "security" personnel. Like landlords, the recipients of any income generated by defensive expenditures are assumed to live outside the city.

The cost of eviction is then an increasing function of defensive expenditures per household, denoted $A$. Since the opposition to evictions is more forceful the larger is the size of the squatter group, eviction cost also rises with $N_{s}$, holding $A$ fixed. ${ }^{4}$ Letting $k$ denote an institutional parameter measuring the difficulty of property-rights enforcement in the economy, eviction cost can then be written $e\left(A, N_{s}, k\right)$, with the effect of $k$ positive.

This eviction cost is expressed on a per-unit-of-land basis, so that $e\left(A, N_{s}, k\right)$ gives the cost of squatter removal for each unit of occupied land. The landowner's gain from eviction is the rental income earned when the seized land is rented in the formal sector, equal to $p_{f}$. Therefore, in order for landowners to find eviction unattractive, the inequality

$$
p_{f} \leq e\left(A, N_{s}, k\right)
$$


must hold. 5 This condition is the "no-eviction" constraint.

As explained in the introduction, the squatter population is governed by a community organizer, who has the power to dictate defensive expenditures $A$ as well as the plot size $q_{s}$. In addition, the organizer is initially assumed to control the size $N_{s}$ of the squatter population, an assumption that is relaxed below. The organizer's goal is to choose these variables to maximize the common utility level of squatter households, who share the same well-behaved preferences. Let $u\left(x_{s}, q_{s}\right)$ denote squatter utility as a function of the consumption of housing (land) and a composite non-housing good $x$. Then, using the budget constraint $x_{s}+A=y_{s}$, the community organizer's goal is to maximize

$$
u\left(y_{s}-A, q_{s}\right)
$$

by choice of $A, q_{s}$ and $N_{s}$ subject to (1)-(5). Given the desirability of setting $A$ at the smallest possible value, the inequality in (5) will hold as an equality at the optimum and can be treated as such in the maximization problem. The maximal value of (6) is assumed to be larger than the rural utility level, denoted $\widetilde{u}$, so that the organizer faces a willing supply of squatters.

The nature of the problem faced by the squatter organizer can be seen by considering the various constraints along with the objective function in (6). First, as mentioned above, setting $A$ at a low value raises $x_{s}$, but the resulting decline in $e\left(A, N_{s}, k\right)$ invites eviction by landowners. In addition, for given $N_{s}$, allowing the plot size $q_{s}$ to expand raises squatter utility but further squeezes the formal housing sector by raising $L_{s}$. The resulting drop in $L_{f}$ then leads to an increase in the formal rent $p_{f}$, again inviting eviction by landowners. Similarly, while a higher $N_{s}$ reduces the threat of eviction, allowing a reduction in $A$, it leads to the same squeezing effect as an increase in $q_{s}$, and the resulting increase in $p_{f}$ reverses the decline in the eviction threat. The squatter organizer must balance these various effects, choosing the best values of the decision variables while ensuring satisfaction of the no-eviction constraint in (5).

\subsection{Optimality conditions}

To solve the organizer's optimization problem, the five constraints in (1)-(5) can be collapsed to a smaller number. First, using (4) and (5), $q_{f}$ can be written as $q_{f}=d_{f}\left(e\left(A, N_{s}, k\right)\right)$. Then combining (1)-(3) yields $N_{s} q_{s}=\bar{L}-\bar{N}_{f} q_{f}$, and substituting the previous solution and 
solving for $q_{s}$ yields

$$
q_{s}=\frac{\bar{L}-\bar{N}_{f} d_{f}\left(e\left(A, N_{s}, k\right)\right)}{N_{s}}
$$

The objective function can then be written as

$$
u\left(y_{s}-A, \frac{\bar{L}-\bar{N}_{f} d_{f}\left(e\left(A, N_{s}, k\right)\right)}{N_{s}}\right),
$$

which is maximized by choice of $A$ and $N_{s}$.

The first-order condition for choice of $A$ reduces to

$$
\frac{u^{x}}{u^{q}}=-\frac{\bar{N}_{f} d_{f}^{\prime} e^{A}}{N_{s}} \equiv \frac{\partial q_{s}}{\partial A}
$$

where superscripts denote partial derivatives. This condition says that the loss from less $x_{s}$ due to a marginal increase in $A$ (given by $\left.u^{x}\right)$ should equal the gain from a higher $q_{s}\left(u^{q} \partial q_{s} / \partial A\right)$. Note that the $\partial q_{s} / \partial A$ expression in the middle of (9) captures the following sequence of effects: the higher $A$ raises eviction costs, allowing $p_{f}$ to rise by $e^{A}$; the resulting reduction in $q_{f}$ is $d_{f}^{\prime} e^{A}$; multiplying by $\bar{N}_{f}$ gives the reduction in $L_{f}$, which equals the increase in $L_{s}$; dividing by $N_{s}$ then yields the increase in $q_{s}$.

Since $N_{s}$ only appears in the $q_{s}$ argument of (8), differentiation of (7) yields the first-order condition for $N_{s}$, which can be written

$$
-\bar{N}_{f} d_{f}^{\prime} e^{N_{s}}=\frac{\bar{L}-\bar{N}_{f} d_{f}}{N_{s}} \equiv q_{s}
$$

To interpret this condition, note that since $q_{s}=L_{s} / N_{s}$ from (2), maximizing $q_{s}$ means maximizing "average" land consumption (total squatter land divided by population). But maximizing the average requires setting the marginal effect of $N_{s}$ equal to the average itself, so that $\partial L_{s} / \partial N_{s}=L_{s} / N_{s}$ holds. The LHS of this equality is just the first expression in (10) (using the previous logic), while $L_{s} / N_{s}$ is the second expression.

For (9) and (10) to yield a maximum, the relevant second-order conditions must be satisfied. For a simple understanding of these conditions, the maximization problem can be viewed as 
being solved sequentially, with $N_{s}$ chosen conditional on $A$ and with $A$ then optimized in a second stage. From this perspective, the second-order conditions will be met if following requirements are satisfied. First, $q_{s}$ from (7) should be a strictly concave function of $N_{s}$, holding $A$ fixed, at least in a neighborhood of the value where the derivative is zero. Then (10), the first-order condition for $N_{s}$, will yield a maximum conditional on $A$. Second, letting $N_{s}^{*}(A)$ be the $N_{s}$ solution from (10) conditional on $A$, and letting $f\left(A, N_{s}\right)$ denote the $q_{s}$ expression in (7), $f\left(A, N_{s}^{*}(A)\right)$ should be a concave function of $A$. Then, the optimization problem involves maximizing $u\left(y-A, q_{s}\right)$ subject to the concave constraint $q_{s}=f\left(A, N_{s}^{*}(A)\right)$. With the utility function well-behaved, the first-order conditions (9) and (10) then jointly yield a maximum. Whether or not these requirements are satisfied depends, of course, on the properties of the $d_{f}(\cdot)$ and $e(\cdot)$ functions.

The solutions for the endogenous variables $A, q_{s}, N_{s}, L_{s}, L_{f}$ and $p_{f}$ depend on the parameters of the problem: $\bar{L}, \overline{N_{f}}, y_{s}, y_{f}, k$, and the parameters of $u(\cdot)$ and $d_{f}$. But given the complexity of the model, a general comparative-static analysis yields ambiguous conclusions. As a result, the next section of the paper presents an example that imposes specific forms for the various functions appearing in the optimization problem. Satisfaction of the second-order conditions can also be verified under these functional forms.

Before turning to the example, several additional points require discussion. First, in order for the above solution to make sense, squatting must be "sustainable": squatters should not be able to raise their utility by entering the formal housing market. A condition on parameters that ensures sustainability is derived for the ensuing example. Second, formal households should not be able to gain by becoming squatters. This possibility is ruled out by assuming that squatting carries a strong enough stigma to make it unattractive under any circumstances for formal households. Such an assumption can be justified by imagining that formal employers engage in spatial "redlining" of workers, refusing to give jobs (or offering lower wages) to individuals living in undesirable areas of the city. See Zenou and Boccard (2000) and Zenou (2002) for detailed analyses of models with this kind of redlining behavior.

\subsection{An example}

To develop an example based on specific functional forms, suppose that squatters and 
formal residents have the common Cobb-Douglas utility function $x^{1-\alpha} q^{\alpha}$, where $0<\alpha<1$. The formal housing demand function is then given by $d_{f}\left(p_{f}\right) \equiv \alpha y_{f} / p_{f}$. In addition, let the eviction-cost function be given by $e\left(A, N_{s}, k\right) \equiv k N_{s} A$, indicating that eviction cost is proportional to the total defensive expenditures of squatters, $A N_{s}$, with the proportionality factor equal to the property-rights parameter $k$. Then, (7) becomes $q_{s}=\left(1 / N_{s}\right)\left(\bar{L}-\alpha y_{f} \bar{N}_{f} / k A N_{s}\right)$, and, as shown in the appendix, the solutions for the endogenous variables are given by

$$
\begin{aligned}
A & =\alpha y_{s} \\
q_{s} & =\frac{k y_{s} \bar{L}^{2}}{4 \bar{N}_{f} y_{f}} \\
N_{s} & =\frac{2 \bar{N}_{f} y_{f}}{k y_{s} \bar{L}} \\
L_{s} & =L_{f}=\frac{\bar{L}}{2} \\
p_{f} & =\frac{2 \alpha \overline{N_{f}} y_{f}}{\bar{L}}
\end{aligned}
$$

These solutions show that squatters devote a fraction $\alpha$ of their income to defensive expenditures. While this outcome is natural given Cobb-Douglas utility, other features of the solution are somewhat surprising. In particular, the amount of land occupied by squatters, $L_{s}$, equals exactly half of the city's land area, regardless of squatter and formal income levels, the strength of property rights, the size of the formal group, or the size of preference parameter $\alpha$. Since $L_{f}$, the supply of land to the formal market, is also independent of these parameters, it follows that the formal price $p_{f}$ depends only on the parameters that affect formal demand $\left(\bar{N}_{f}, y_{f}\right.$, and $\left.\alpha\right)$, being independent of $y_{s}$ and $k$. Thus, the extent of squeezing of the formal market is curiously independent of these two key features of the squatter environment. By contrast, all of the model's parameters (aside from $\bar{L}$ ) affect how the fixed squatter land area is allocated, determining whether the area has a large number of squatters and small plots or, alternatively, few squatters and large plots. The latter outcome obtains when $k$ or the income ratio $y_{s} / y_{f}$ is large, or when $\bar{N}_{f}$ is small. 


\subsection{Formalization and the impact of squatting on formal households}

Because the extent of squeezing of the formal market by squatters is independent of the model's parameters, the solution in (11)-(15) tends to obscure the welfare impact of squatting on formal residents. To highlight that impact, it is useful to ask a broader question that goes beyond the comparative-static exercise from above. In particular, how does the very existence of squatting affect formal residents? In other words, if the squatter households were "formalized," being forced to pay for the land they occupy, would the original formal households be better off? Answering this question will also lead to an analysis of squatter formalization as a policy option.

To answer the given question, another issue must be addressed first: sustainability of the squatter equilibrium. In order for the equilibrium characterized by (11)-(15) to be sustainable, squatter households should not be able to gain by individually opting out, switching to formal residence at the prevailing formal rental price. Using the Cobb-Douglas demand functions, the $x$ and $q$ consumption levels following such a switch equal $(1-\alpha) y_{s}$ and $\alpha y_{s} / p_{f}$, respectively. The condition for the absence of a gain is then

$$
\left[(1-\alpha) y_{s}\right]^{1-\alpha}\left(\alpha y_{s} / p_{f}\right)^{\alpha}<\left(y_{s}-A\right)^{1-\alpha} q_{s}^{\alpha} .
$$

Note that since $A=\alpha y_{s}, x$ consumption is the same on both sides of (16), which implies that the inequality holds if $q$ is lower after the switch. Substituting for $p_{f}$ and $q_{s}$ from (12) and (15) and rearranging, (16) reduces to the condition

$$
k \bar{L}>2 .
$$

Therefore, for the squatter equilibrium to be sustainable, the city land area weighted by the property-rights parameter should be sufficiently large.

Using this result, the welfare impact of squatting on formal residents can be derived, answering the above question. This impact is found by computing the formal price that would prevail if the equilibrium group of squatter households were formalized, becoming formal 
residents. If that price is lower than the $p_{f}$ solution in (15), then formal residents are harmed by squatting.

If squatters were formalized, the aggregate demand function for land in the city would be given by $\alpha\left(N_{s} y_{s}+\bar{N}_{f} y_{f}\right) / p_{f}$. This demand is larger than the demand from formal households alone, but formalization also means a doubling of the supply of land to the formal sector, from $\bar{L} / 2$ to $\bar{L}$. Setting demand equal to $\bar{L}$ and substituting for $N_{s}$ from (13), the new equilibrium price would equal

$$
\widehat{p}_{f}=\frac{\alpha\left(N_{s} y_{s}+\bar{N}_{f} y_{f}\right)}{\bar{L}}=\frac{\alpha\left[2 \bar{N}_{f} y_{f} / k \bar{L}+\bar{N}_{f} y_{f}\right]}{\bar{L}}
$$

However, using the sustainability condition (17), it follows that

$$
\widehat{p}_{f}<\frac{2 \alpha \bar{N}_{f} y_{f}}{\bar{L}}=p_{f}
$$

Thus, when the squatter equilibrium is sustainable, the formal price would be lower if all squatters were formalized. As a result, formalization benefits existing formal households.

Note that, with a lower rental price, individual and thus total land consumption by the original formal households is higher after the squatters have been formalized. Instead of equally splitting the city's land area, the original formal residents then occupy an area larger than $\bar{L} / 2$, while the original squatters occupy a smaller area. Thus, squeezing of the formal housing market is relaxed by formalization.

With the total land area occupied by squatters lower after formalization and their number held fixed by assumption, individual land consumption is lower as well. Given that $x$ consumption remains the same at $(1-\alpha) y_{s}$, it follows that squatters are worse off following formalization. Summarizing yields

Proposition 1. Under the maintained functional-form assumptions, formal residents benefit from formalization of squatter households, indicating that they are harmed by squatting. Conversely, squatter households are made worse off by formalization.

Recall that, when (17) holds, a single squatter household is worse off when it alone is switched to formal tenure (which leaves the formal price unaffected). Proposition 1, however, 
indicates that the welfare of each squatter household falls when the entire group is formalized, even though this event leads to a decline in the formal price. Interestingly, the sustainability condition (17) is necessary and sufficient for a decline squatter welfare in both cases, even though they involve different formal prices. ${ }^{6}$

\subsection{Inefficiency of the squatter equilibrium}

While squatters lose when they are formalized, could formal households offer compensation for this loss while still enjoying a net gain? To address this question, the first step is to note that, since such compensation is just an income transfer, it leaves total income unchanged and thus has no effect (under Cobb-Douglas preferences) on the price $\widehat{p}_{f}$ that prevails in the new equilibrium where everyone is a formal resident. Therefore the analysis can proceed by computing compensating variations while holding $\widehat{p}_{f}$ fixed.

The compensating variation for squatters, denoted $C_{s}$, equals the addition to income that allows each squatter household to achieve its original utility in the new equilibrium, and it satisfies

$$
\left(y_{s}-A\right)^{1-\alpha} q_{s}^{\alpha}=\left[(1-\alpha)\left(y_{s}+C_{s}\right)\right]^{1-\alpha}\left[\alpha\left(y_{s}+C_{s}\right) / \widehat{p}_{f}\right]^{\alpha} .
$$

Substituting the previous solutions for $A, q_{s}$ and $\widehat{p}_{f}$ and solving yields

$$
C_{s}=y_{s}\left[\left(\frac{1}{2}+\frac{k \bar{L}}{4}\right)^{\alpha}-1\right]
$$

Note that $C_{s}$ is appropriately positive when the sustainability condition $k \bar{L}>2$ holds, indicating an uncompensated loss from formalization.

Similarly, the compensating variation for formal households, denoted $C_{f}$, equals the income loss that reduces their utility following formalization to the original level, and it satisfies

$$
\left[(1-\alpha) y_{f}\right]^{1-\alpha}\left(\alpha y_{f} / p_{f}\right)^{\alpha}=\left[(1-\alpha)\left(y_{f}-C_{f}\right)\right]^{1-\alpha}\left[\alpha\left(y_{f}-C_{f}\right) / \widehat{p}_{f}\right]^{\alpha}
$$

Substituting the previous solutions and solving yields

$$
C_{f}=y_{f}\left[1-\left(\frac{1}{2}+\frac{1}{k \bar{L}}\right)^{\alpha}\right]
$$


a positive expression when $k \bar{L}>2$.

In order for compensation of the former squatter households to be feasible, the inequality

$$
\bar{N}_{f} C_{f}>N_{s} C_{s}
$$

must hold, indicating that the outlay that keeps formal households at their original utility level is more than sufficient to keep former squatters at their original utility. Substituting for $N_{s}$ and using (21) and (23), the inequality in (24) reduces to

$$
\frac{k \bar{L}}{2}\left(1-\left(\frac{1}{2}+\frac{1}{k \bar{L}}\right)^{\alpha}\right)+1-\left(\frac{1}{2}+\frac{k \bar{L}}{4}\right)^{\alpha}>0
$$

Since the appendix shows that this inequality is satisfied, it follows that formal households can compensate squatters for the losses they incur in being formalized. Note that if the compensation were designed to keep squatters at their original utility level, each formal household would contribute an amount equal to $T \equiv N_{s} C_{s} / \bar{N}_{f}<C_{f}$ from (24).

While this result points toward an inefficiency verdict in evaluating the squatter equilibrium, the economy has two additional stakeholder groups whose welfare must be considered. Absentee landowners clearly are affected by squatting, and their income in the original equilibrium is equal to $p_{f} \bar{L} / 2=\alpha \overline{N_{f}} y_{f}$. Although the rental price falls, the area generating land rent doubles when the squatters are formalized, yielding total income of $\widehat{p}_{f} \bar{L}=\alpha \bar{N}_{f} y_{f}(2 / k \bar{L}+1)$. Subtracting, landowners then enjoy a gain of

$$
\widehat{p}_{f} \bar{L}-p_{f} \bar{L} / 2=2 \alpha \bar{N}_{f} y_{f} / k \bar{L}
$$

Another potential stakeholder group, the recipients of income from squatter defensive expenditures (political operatives, for example), must also be considered. These expenditures, which equal $A N_{s}$ in total, disappear when the squatters are formalized, resulting in an income loss of this magnitude for the recipients. Remarkably, however, the lost income of $A N_{s}$ exactly equals the gain to absentee landowners in (26), as can be seen by substituting the $A$ and $N_{s}$ solutions. Therefore, landowners can exactly compensate these income recipients for their loss. 
Summarizing the foregoing results yields ${ }^{7}$

Proposition 2. The squatter equilibrium is inefficient. In particular, if squatter households were formalized, the gainers (original formal residents, absentee landowners) could compensate the losers (former squatters, recipients of defensive expenditures) for their losses.

Note that another population group, potential squatters who remain in rural areas, is unaffected by the switch and need not be considered.

The inefficiency of the squatter equilibrium is, from one perspective, not very surprising. However, since this finding requires comparisons of the outcomes under two different behavioral regimes (squatting vs. formal residence), it differs from a typical inefficiency verdict, which focuses on the gain from removing a distortion within a single institutional framework. The source of the inefficiency in the present model is evidently the absence of mutually accepted transactions between squatters and landowners, which constitutes a market failure that allows room for general improvement when squatters are formalized. ${ }^{8}$

Although the model is highly stylized, making the results only suggestive, they do provide a possible lesson for public policy. Even though Proposition 2 refers to a forcible formalization of squatters, it implies that formal households could induce squatters to become formal residents through suitable compensation, after which both groups would be better off. The analysis thus suggests that a mutually agreeable transition out of a squatter equilibrium is possible, which involves income transfers from formal to squatter households.

\subsection{Formalization and land servicing}

The harmful impact of formalization on squatter households needs to be qualified given that formalization programs are almost always accompanied by some degree of improvement in infrastructure and land servicing, as provided by the local government. In other words, while formalized squatters tend to incur a loss from their exposure to the market price of land, they may benefit from improved access to infrastructure and land services. Whether the net outcome is beneficial depends on the relative intensities of the two effects, as well as on the financing of the policies. In particular, whether the cost of infrastructure improvements should be recovered from the beneficiaries or subsidized has been at the center of a debate for years. 
In practice, the full-cost recovery of slum-upgrading projects may prove difficult (Buckley and Kalarickal, 2006), so that infrastructure improvements may require subsidies to cover all or part of the cost.

The model allows a straightforward discussion of infrastructure improvements and land servicing, financed by taxes on the original formal residents. These taxes take the place of the cash transfers discussed above. Suppose that formal occupancy requires servicing of the land, at a cost of $g$ per household. ${ }^{9}$ Before formalization of the squatters, formal households pay only for the servicing of their own land through taxes, so that their budget constraint is $g+x_{f}+p_{f} q_{f}=y_{f}$. Assuming that land services are a perfect substitute for $x$ consumption (recall that $x$ is a composite, non-housing good), formal utility is then $u\left(g+x_{f}, q_{f}\right)=u\left(y_{f}-p_{f} q_{f}, q_{f}\right)$, leaving the objective function of formal households the same as without land servicing. If formal households were to pay an additional tax of $t$ to finance provision of services on former squatter land, utility would become $u\left(y_{f}-t-p_{f} q_{f}, q_{f}\right)$.

The magnitude of the tax $t$ depends on the level of these services, denoted $h$. While $h$ could equal $g$, indicating equal service provision throughout the city, $h<g$ would hold if inferior services are provided to formalized land. Given $h$, the tax on the original formal households must then equal $t=N_{s} h / \bar{N}_{f}$.

The servicing expenditure of $h$ effectively increases $x$ consumption for the former squatters and helps to offset the utility loss from facing the market price of land. ${ }^{10}$ If $h>C_{s}$ from (21), then the benefits from land servicing are more than enough to offset this loss. However, if $h<C_{s}$ holds, then the original formal households must offer an additional cash transfer of $r=N_{s} C_{f} / \bar{N}_{f}-t$ to induce squatters to accept formalization. Instead of paying $t$, their payment is then $t+r=N_{s} C_{f} / \bar{N}_{f} \equiv T$.

This discussion shows that the land servicing requirement has no effect on the preceding analysis, with the required servicing outlay simply encompassed in the transfer from formal to squatter households. ${ }^{11}$ Note, however, that this conclusion is overturned if the tax required to support servicing costs exceeds the amount formal households are willing to pay for formalization (if $t>C_{f}$ ). Then, voluntary formalization cannot occur unless additional outside resources can be found for squatter compensation. ${ }^{12}$ 


\subsection{Squatting on government or marginal land}

Squatters often occupy land that is government-owned or marginal in quality, where eviction is less of a threat than on prime land. The model applies to this case as well, under a particular assumption. To see the argument, let $L_{g}$ denote the amount of vacant government land in the city (alternatively, this could be land of marginal quality). Assuming the threat of eviction is low on such land, it will be fully occupied by squatters. But suppose the gains from squatting are sufficient to induce occupation of some prime land as well, with the amount of

such land denoted $\widetilde{L}_{s}$, which satisfies $\widetilde{L}_{s}+L_{g}=L_{s}$. Then, the no-eviction constraint (5) becomes relevant, and the previous equilibrium conditions again apply. This argument assumes, however, that the squatters occupying government land are required by the organizer to make the same defensive outlay $A$ as squatters on prime land, even though their eviction threat is lower, while also consuming a plot of the same size. These requirements are plausible given that the totality of defensive expenditures by squatters, both on prime and government land, may be relevant in deterring the eviction threat on prime land.

\section{Uncontrolled Squatter Migration}

\subsection{Basic analysis}

So far, the squatter population size has been controlled by the organizer, who has the power to limit migration into the city. Since this assumption may be unrealistic, however, it is useful to explore the case where migration cannot be controlled. In this case, $N_{s}$ is no longer a decision variable of the squatter organizer, who now chooses $A$ to maximize (8) viewing $N_{s}$ as parametric (satisfying (9)). ${ }^{13}$ The previous first-order condition (10) for $N_{s}$ is replaced by a new equilibrium condition, which says that squatter utility equals $\widetilde{u}$, the prevailing level in rural areas:

$$
\left(y_{s}-A\right)^{1-\alpha} q_{s}^{\alpha}=\widetilde{u},
$$

where $q_{s}$ is given by (7). Thus, squatter migration will proceed up to the point where the gain relative to rural living is exhausted. Note that the squatter organizer attempts to maximize utility through choice of $A$ even though migration ultimately forces utility down to the rural 
level. Eqs. (27) and (9) determine the values of $A$ and $N_{s}$ in the uncontrolled-migration equilibrium.

Unlike in the earlier analysis, closed-form equilibrium solutions are not available for the controlled-migration case under the functional form assumptions of the example. In addition, comparative-static analysis of the equilibrium does not produce determinate results. Nevertheless, some useful comparisons between the equilibria with controlled and uncontrolled migration can be derived. To begin, consider Figure 1, which shows squatter utility as a function of $N_{s}$, where $A$ has been chosen optimally conditional on $N_{s}$ (via (9)). ${ }^{14}$ When the organizer can control migration, $N_{s}$ is chosen to maximize squatter utility, leading to the value of $N_{s}^{*}$ in the figure (equal to (13)) and a utility level of $u^{*}$. In the uncontrolled equilibrium, however, the squatter population expands up to $\widetilde{N}_{s}>N_{s}^{*}$, exhausting the gain from migration. Note that, while another value of $N_{s}$ lying below $N_{s}^{*}$ also leads to a squatter utility of $\widetilde{u}$ (see Figure 1), this outcome represents an unstable equilibrium. ${ }^{15}$

Relative to the controlled equilibrium, the impact of uncontrolled migration can thus be analyzed by deriving the effect of a parametric increase in $N_{s}$ on the remaining variables of the model. Relying on the example, the first step is to derive the impact on defensive expenditures $A$. Solving (9), which is a quadratic equation in $A$ (see (a3) in the appendix), yields

$$
A=\frac{\Phi}{N_{s}}+\sqrt{\left(\frac{\Phi}{N_{s}}\right)^{2}+\frac{\Omega}{N_{s}}}
$$

where $\Phi$ and $\Omega$ are positive expressions. ${ }^{16}$ Inspection of (28) shows that $\partial A / \partial N_{s}<0$ holds, indicating that defensive expenditures fall in moving to the uncontrolled-migration equilibrium. To derive the impact on the formal price, multiplication of (28) by $N_{s}$ and use of $p_{f}=k A N_{s}$ from (5) yields $p_{f}=k\left(\Phi+\sqrt{\Phi+\Omega N_{s}}\right)$, an increasing function of $N_{s}$. Therefore, the formal price rises moving from the controlled to the uncontrolled-migration equilibrium, leading to a decline in the formal land area $L_{f}$ and an increase in $L_{s}$. Thus, uncontrolled migration leads to greater squeezing of the formal market, as intuition would suggest. Finally, since $u\left(y_{s}-A, q_{s}\right)=\widetilde{u}<u^{*}$ holds while $A$ falls, it follows that $q_{s}$ must be lower with uncontrolled 
migration. Note that the increase in $N_{s}$ offsets this decline in $q_{s}$, leading to the increase in the squatter land area. Summarizing yields

Proposition 3. In moving from the controlled squatter equilibrium to the uncontrolledmigration equilibrium, the squatter population $N_{s}$ rises. In response, defensive expenditures $A$, the squatter plot size $q_{s}$, and the formal land area $L_{f}$ fall, while the squatter land area $L_{s}$ and the formal price $p_{f}$ rise. The welfare of formal residents declines.

A sustainability condition is again required to ensure the viability of the uncontrolledmigration equilibrium. This condition once again requires satisfaction of (16), but given (27), sustainability reduces to the requirement

$$
\widetilde{u}>\left[(1-\alpha) y_{s}\right]^{1-\alpha}\left(\alpha y_{s} / p_{f}\right)^{\alpha}
$$

which must hold at the new equilibrium value of $p_{f}$. In the absence of closed-form solutions, however, this condition cannot be reduced to a parametric statement like (17).

With uncontrolled migration, the analysis of squatter formalization differs from the previous case. While squatters previously required compensation to accept formalization, rural migrants now receive a utility of $\widetilde{u}$ regardless of the city's institutional arrangement, given the unlimited supply of new households at this reservation utility level. As a result, if squatters were formalized, their equilibrium utility would be unaffected. However, assuming that the initial squatter equilibrium was sustainable, the original formal households would be better off. This conclusion follows because the new migration equilibrium condition is $\widetilde{u}=\left[(1-\alpha) y_{s}\right]^{1-\alpha}\left(\alpha y_{s} / p_{f}\right)^{\alpha}$, which ensures that rural migrants, now living in formal housing, achieve the rural utility level. This condition, which determines $p_{f}$, yields a value lower than in any sustainable squatter equilibrium (compare (29)), implying a gain for the original formal residents. So even though formal residents would be willing to pay squatters to formalize, the squatters themselves require no compensation, at least in equilibrium.

The two other stakeholder groups, however, would again be affected by formalization. While the recipients of income from defensive expenditures would again lose, the effect on absentee landowners is ambiguous in the absence of closed-form solutions. Assuming that 
losses within these two stakeholder groups can be compensated (possibly with help from formal residents), the previous inefficiency verdict would again apply.

\subsection{Numerical solutions for the uncontrolled-migration case}

Given the absence of closed-form solutions in the uncontrolled-migration case, it is useful to compute numerical solutions instead. Such solutions can indicate some of the comparativestatic properties of the squatter equilibrium, while allowing the sustainability condition to be checked. In addition, the solutions allow a more-definite verdict on the inefficiency of the squatter equilibrium.

The base case for the simulation assumes the following parameter values: $\alpha=0.4, y_{s}=$ 0.5, $y_{f}=3, k=1, \bar{L}=10, \bar{N}_{f}=5, \widetilde{u}=0.4$. Given the stylized nature of the model, assignment of parameter values must be completely arbitrary, a fact reflected in these choices. The first finding from the simulations is that the sustainability condition is satisfied both for these parameters values and for values in a wide neighborhood containing them. The second finding is that, in this neighborhood, formalization of squatter households raises the total income of landowners, with their gain being larger than the income loss for recipients of defensive expenditures. Therefore, within the given parameter neighborhood, formalization can make all stakeholders at least as well off as in the squatter equilibrium, indicating the inefficiency of that equilibrium.

While the stylized model and arbitrary nature of the parameter choices makes exhaustive reporting of numerical comparative-statics inappropriate, it is interesting to consider the effect of changes in one key parameter: the property-rights parameter $k$. Variation in this parameter had no effect on the squeezing of the formal market in the controlled-migration model, but an impact emerges with uncontrolled migration. Table 1 shows how moving from a weak propertyrights regime $(k=1.2)$ to a stronger regime $(k=1)$ affects the values of the endogenous variables (other parameters are held at their base-case values). As intuition would suggest, stronger property rights, which lower the cost of evicting squatters, limit the squeezing of the formal market. A decrease in $k$ from 1.2 to 1 reduces the formal price $p_{f}$, benefiting formal residents. The formal land area $L_{f}$ expands, and the squatter area $L_{s}$ shrinks. The squatter population $N_{s}$ falls as $k$ drops, while defensive expenditures $A$ rise, reducing $x$ consumption. 
Moving along the fixed $\widetilde{u}$ indifference curve, individual squatter land consumption $q_{s}$ then rises.

These results suggest an interesting possibility: if property rights could be strengthened through costly institutional investment by formal residents, the gain from reduced squeezing of the formal market may be large enough to make such expenditures worth undertaking. Indeed, if the per capita cost of achieving a level $k$ for the property-rights parameter were given by the smoothly decreasing function $c(k)$, then the "optimal" stringency of property rights would be achieved when $-c^{\prime}(k)$ equals the dollar value of the utility gain from the marginal reduction in squeezing. For a fully developed model of this kind of "investment" in property rights, see Kumar (2007).

\section{Conclusion}

This paper has offered a new theoretical approach to urban squatting, reflecting the view that squatters and formal residents compete for land within a city. The key implication of this view is that squatters "squeeze" the formal market, raising the price paid by formal residents. The squatter organizer, however, ensures that this squeezing is not too severe, since otherwise the formal price will rise to a level that invites eviction by landowners. Because eviction is thus absent in equilibrium, the model differs crucially from previous analytical frameworks, where eviction occurs with some probability.

The main policy lesson of the model is that formalization of squatter households can make both squatters and formal residents better off. Formal residents are willing to pay for the reduction in squeezing that accompanies formalization, and the analysis shows that they can pay enough to compensate squatters for their loss in the transition to formal tenure. In practice, this payment could come in the form of infrastructure investments in squatter areas, financed by taxes on formal households. An important implication of this finding is that squatter formalization may not require external funding from international agencies. Gains to formal households could be sufficient to allow funds to be raised through voluntary transfers within the city.

The model is stylized, and future work could be devoted to relaxing some of its assumptions. For example, instead of having a fixed land area, the supply of urban land could be elastic, a 
modification that should leave the main lessons of the analysis unaffected. Housing investment could be added to the model by allowing both formal and squatter households to add capital to the land. While self-construction is literally an accurate portrayal for squatters, this approach is equivalent in the formal sector to a model where housing developers build structures. Again, the lessons of the analysis would be unaffected by this embellishment.

While the model currently views all households as renters, resident landownership would be another useful modification (replacing absentee ownership). In this case, formal residents would own all the land in the city, paying rent to themselves for the land they occupy while receiving no rent from squatters. Formalization of squatters would then boost the rental income of the original formal residents, an effect not currently present in the model. Note that formalization in this context could alternatively require squatters to purchase the land they occupy from the formal owners, making a large lump sum payment rather than a stream of rental payments. This type of formalization has been observed in Buenos Aires (see Galiani and Schargrodsky, 2004, and Di Tella et al., 2007). While squatters would then acquire title to the land, another approach would be much more lenient: squatters could receive title without any formal payment, an outcome that would clearly benefit them (defensive expenditures could cease).

An additional modification would recognize that squatters benefit formal households by offering complementary, low-skill services in the labor market. This effect, which would cause the formal income $y_{s}$ to rise with the size of the squatter population, would affect the equilibrium value of $N_{s}$. However, it would not alter the analysis of formalization, which holds the squatter population fixed.

Finally, a last extension could modify the model's extreme view of formalization by analyzying an intermediate case, where only a portion of the squatter population is formalized. Such partial formalization will affect the welfare of both the original formal households and the remaining squatters, adding new dimensions to the analysis. Given the importance of squatting as a worldwide phenomenon, this kind of additional theoretical work, as well as further well-targeted empirical research, deserves high priority. 


\section{Appendix}

A1. Solving for the squatting equilibrium under the example

Under the maintained assumptions, (7) reduces to

$$
q_{s}=\frac{\bar{L}-\bar{N}_{f} \beta / A N_{s}}{N_{s}}
$$

where $\beta \equiv \alpha y_{f} / k$. With Cobb-Douglas preferences, the objective function is then

$$
\left(y_{s}-A\right)^{1-\alpha}\left(\frac{\bar{L}-\bar{N}_{f} \beta / A N_{s}}{N_{s}}\right)^{\alpha},
$$

and the first-order conditions for $A$ and $N_{s}((9)$ and (10)) reduce to

$$
\begin{aligned}
-(1-\alpha)\left(\bar{L} N_{s} A^{2}-\beta \bar{N}_{f} A\right)+\alpha\left(y_{s}-A\right) \beta \overline{N_{f}} & =0 \\
\beta \bar{N}_{f} / A N_{s}^{2}-\left(\bar{L}-\beta \overline{N_{f}} / A N_{s}\right) / N_{s} & =0 .
\end{aligned}
$$

Rearrangement of (a4) yields

$$
A N_{s}=2 \beta \overline{N_{f}} / \bar{L}
$$

and substitution in (a3) yields $A=\alpha y_{s}$ after rearrangement. Substitution of this $A$ solution into (a5) then yields $N_{s}$, and further substitution into the constraints of the problem gives solutions for the remaining variables.

To verify satisfaction of the second-order conditions, note first that the second derivative of (a1) with respect to $N_{s}$ is negative when evaluated at the $N_{s}$ solution (conditional on $A$ ) given by (a5). Therefore, conditional on $A, q_{s}$ is a strictly concave function of $N_{s}$ near the value where the derivative is equal to zero, as required for the first-order condition in (a4) to yield a maximum. Next, note that solving $(a 5)$ for $N_{s}$ conditional on $A$, and then substituting the

result into ( $a 1$ ), yields $q_{s}=\bar{L}^{2} A / 4 \bar{N}_{f} \beta$, a linear function. Thus, under the two-stage view of 
the optimization problem, the (well-behaved) utility function is being maximized with respect to $A$ in the second stage subject to a linear constraint, ensuring that the resulting first-order condition yields an optimum.

A2. The sign of (25)

Letting $b \equiv k \bar{L},(25)$ can be written

$$
\begin{aligned}
& \frac{b}{2}\left(1-\left(\frac{1}{2}+\frac{1}{b}\right)^{\alpha}\right)+1-\left(\frac{1}{2}+\frac{b}{4}\right)^{\alpha} \\
= & \frac{b+2}{2}-\frac{b}{2}\left(\frac{b+2}{2 b}\right)^{\alpha}-\left(\frac{b+2}{4}\right)^{\alpha} \\
= & \frac{b+2}{2}-\left(\frac{b}{2}\right)^{1-\alpha}\left(\frac{b+2}{4}\right)^{\alpha}-\left(\frac{b+2}{4}\right)^{\alpha} \\
= & \frac{b+2}{2}\left[1-\left(1+\left(\frac{b}{2}\right)^{1-\alpha}\right)\left(\frac{b+2}{2}\right)^{\alpha-1}\left(\frac{1}{2}\right)^{\alpha}\right] .
\end{aligned}
$$

The series of terms following the 1 inside the large brackets in $(a 6)$ is less than unity, establishing positivity of the expression. This fact can be demonstrated by rewriting these terms as

$$
\frac{1}{2}\left(1+\left(\frac{b}{2}\right)^{1-\alpha}\right)\left(\frac{1}{2}\right)^{\alpha-1}\left(1+\frac{b}{2}\right)^{\alpha-1},
$$

which will be less than unity when

$$
\left(\frac{1}{2} \cdot 1^{1-\alpha}+\frac{1}{2} \cdot\left(\frac{b}{2}\right)^{1-\alpha}\right)<\left(\frac{1}{2} \cdot 1+\frac{1}{2} \cdot \frac{b}{2}\right)^{1-\alpha}
$$

This inequality holds by the definition of strict concavity, as applied to the strictly concave function $z^{1-\alpha}$. 


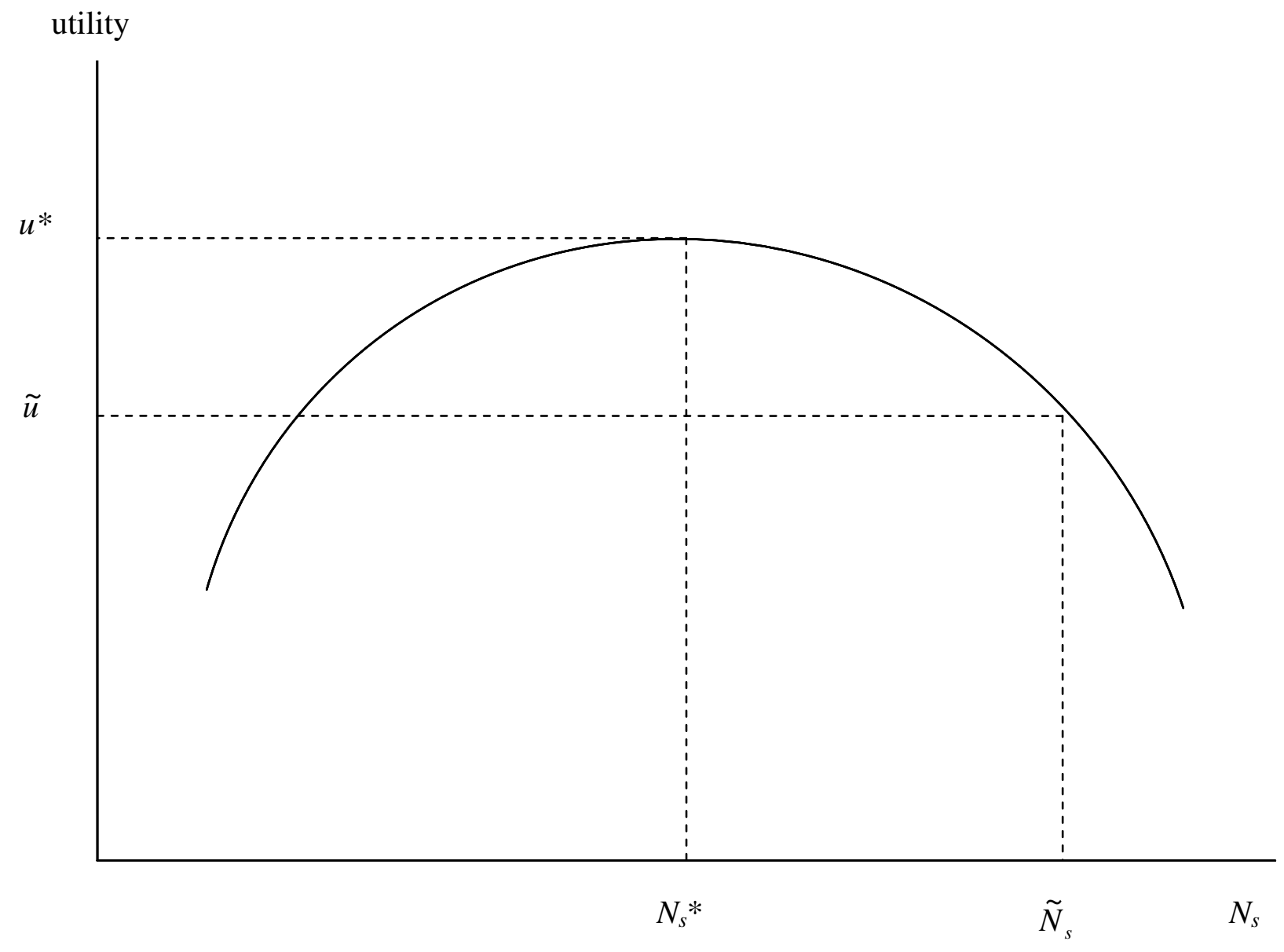

Figure 1: The uncontrolled-migration equilibrium 
Table 1

The Effect of Property-Rights Strengthening with Uncontrolled Migration

\begin{tabular}{lcc}
\hline \hline & $\begin{array}{c}\text { Weak Property Rights } \\
(k=1.2)\end{array}$ & $\begin{array}{c}\text { Strong Property Rights } \\
(k=1)\end{array}$ \\
\hline$p_{f}$ & 2.19 & 1.88 \\
$L_{f}$ & 2.75 & 3.19 \\
$L_{s}$ & 7.25 & 6.81 \\
$N_{s}$ & 18.09 & 15.84 \\
$A$ & 0.10 & 0.12 \\
$q_{s}$ & 0.40 & 0.43 \\
\hline \hline
\end{tabular}




\section{References}

Buckley R., Kalarickal J., 2006. Thirty Years of World Bank Shelter Lending. What Have we Learned? World Bank, Washington DC.

Davis M., 2006. Planet of Slums. Verso, London and New York.

Deininger K., 2003. Land Policies for Growth and Poverty Reduction. World Bank / Oxford University Press.

Di Tella R., Galiani S., Schargodsky E., 2007. The formation of beliefs: evidence from the allocation of land titles to squatters. Quarterly Journal of Economics 122, 209-241.

Duranton G., 2007. From cities to productivity and growth in developing countries. Unpublished paper, University of Toronto.

Durand-Lasserve A., Selod H., 2007. The formalisation of urban land tenure in developing countries. Paper prepared for the World Bank's 2007 Urban Research Symposium.

Farvacque-Viktovic C., Godin L., Leroux H., Verdet F., Chavez R., 2005. Street Addressing and the Management of Cities. World Bank, Washington DC.

Feder G., Nishio A., 1998. The benefits of land registration and titling: economic and social perspectives. Land Use Policy 15, 25-43.

Feder G., Onchan T., Chalamwong Y., Hongladarom C., 1988. Land Policies and Farm Productivity in Thailand. Johns Hopkins University Press, Baltimore and London.

FiELD E., 2005. Property rights and investment in urban slums. Journal of the European Economic Association, Papers and Proceedings 3, 279-290.

FIELD E., 2007. Entitled to work: Urban property rights and labor supply in Peru. Quarterly Journal of Economics 122, 1561-1602.

Flood J., 2006. Secure tenure survey final report. A report prepared for the Urban Growth Management Initiative.

Friedman J., Jimenez E., Mayo S., 1988. The demand for tenure security in developing countries. Journal of Development Economics 29, 185-198.

Galiani S., Schargrodsky E., 2004. Effects of land titling on child health. Economics and Human Biology 2, 353-72. 
Hoy M., Jimenez E., 1991. Squatters rights and urban development: an economic perspective. Economica 58, 79-92.

Jimenez E., 1984. Tenure security and urban squatting. Review of Economics and Statistics $66,556-67$.

JimenEz E., 1985. Urban squatting and community organization in developing countries. Journal of Public Economics 27, 69-92.

Kumar V., 2007. Production, appropriation, and the dynamic emergence of property rights. Unpublished paper, UC Irvine.

LAnjouw J., Levy P., 2002. Untitled: A study of formal and informal property rights in urban Ecuador. Economic Journal 112, 986-1019.

LAll S., Lundberg M., Shalizi Z., 2008. Implications of alternate policies on welfare of slum dwellers: evidence from Pune, India. Journal of Urban Economics 63, 56-73.

MANGIN W., 1967. Latin American squatter settlements: a problem and a solution. Latin American Research Review 2, 65-98.

Neuwirth R., 2005. Shadow Cities: A Billion Squatters, A New Urban World. Routledge, New York.

Turnbull G., 2004. Squatting, eviction, and development. Andrew Young School of Policy Studies Working Paper No. 04-07, Georgia State University.

United Nations Habitat, 2003. The Challenge of Slums / Global Report on Human Settlements 2003. UN-Habitat / Earthscan, London.

World BAnk, 1993. Housing: Enabling Markets to Work. World Bank, Washington DC.

World BAnK, 2007. Dhaka: improving living conditions for the urban poor. World Bank, Bangladesh Development Series Paper No.17.

Zenou, Y., Boccard, N., 2000. Racial discrimination and redlining in cities. Journal of Urban Economics 48, 260-285.

Zenou, Y., 2002. How do firms redline workers? Journal of Urban Economics 52, 391-408. 


\section{Footnotes}

*This paper was written while the second author was a visiting researcher at the World Bank. He wishes to thank the World Bank for its sponsorship and in particular Marisela Montoliu Munoz, Gershon Feder, Somik Lall, and Uwe Deichman. The first author thanks the Gould Foundation for support, and both authors are grateful to Patricia Annez, Judy Baker, Bob Buckley, Klaus Deininger, Mila Freire, Ami Glazer, Jean-Jacques Helluin, Kangoh Lee, Ashna Mathema, Robin Rajack, and seminar participants at the World Bank for their conversations and comments. The findings, interpretations, and conclusions expressed in this paper are ours and do not represent the view of the World Bank, its Executive Directors, or the countries they represent.

${ }^{1}$ Alternatively, the squatter organizer's objective could to be to maximize his own profit (extorting money from squatters while devoting part of that money to defensive expenditures). Whether community organizers are considered benevolent agents or rent seekers would not greatly change the qualitative implications of the model.

${ }^{2}$ De jure formalization is not the only type of possible intervention in squatter settlements. Other types of interventions, such as street addressing (Farvacke et al., 2005) may simply seek the de facto recognition of occupancy (see Durand-Lasserve and Selod, 2007, for more details). Other direct interventions consist of improving the housing and living conditions of squatters (for a discussion of slum upgrading, see Lall et al., 2008).

${ }^{3}$ The city's rental income is then spent elsewhere, with local incomes having no rental-income component.

${ }^{4}$ It could be argued that a very large population size reduces the cohesion of the squatter group, causing eviction cost to fall with $N_{s}$ at large values.

${ }^{5}$ An alternate approach would be to assume that the $e$ function gives the eviction cost for an entire squatter parcel, not per unit of land. Then, (5) would be replaced by $p_{f} q_{s} \leq$ $e\left(A, N_{s}, k\right)$, with the LHS giving the formal rent that would be earned by the squatter parcel. This alternate formulation yields conclusions very similar to those reached using (5) while introducing some additional complexity.

${ }^{6}$ This conclusion can also be seen by evaluating (16) with $\widehat{p}_{f}$ in place of $p_{f}$. Note that while (16) previously reduced to $k \bar{L}>2$, (16) with $\widehat{p}_{f}$ in place of $p_{f}$ reduces to $k \bar{L}>4 /(2 / k \bar{L}+1)$. Since the RHS of the last inequality exceeds 2 when $k \bar{L}>2$, the inequality is satisfied by a narrower margin, indicating the loss from switching to formal residence is smaller when the rental price is lower, at $\widehat{p}_{f}$. But after rearrangement, the inequality reduces to $k \bar{L}>2$, the 
original sustainability condition.

${ }^{7}$ This result and the subsequent Proposition are conditional on the maintained functionalform assumptions.

${ }^{8}$ To put this result into context, observe that the literature on land tenure formalization, both for rural areas (see Feder et al., 1988, Feder and Nishio, 1998, and Deininger, 2003) and for urban areas (see Field, 2005 and 2007, Galiani and Schargrodsky, 2004, Di Tella et al., 2007), exclusively focuses on some specific potential consequences of land titling such as capital investment, labor market participation or health improvement. None of these works focuses on the redistribution effects of formalization in a unified land-market framework.

${ }^{9}$ This cost is the annualized capital cost of infrastructure plus the recurring cost of services.

${ }^{10}$ It can easily be checked that the equilibrium land price is the same as in the case without land services, a consequence of the fact that the provision of services is equivalent to a cash transfer.

${ }^{11}$ Observe that an alternative way of modeling the benefits of improved infrastructure to formalized households could relax the assumption of perfect substitution between services and $x$ consumption. For instance, preferences could be represented by a separable utility function of the form $u(x, q)+v(g)$. Assuming that $v^{\prime}(0)$ is large, formalized squatters would receive a large benefit from even a small level of services as opposed to none at all. Under this new assumption, only a small transfer from formal households would be required to compensate formalized households for their exposure to market prices. It might even be the case that no transfer at all is needed, so that formalized households would gain even when bearing the full cost of services themselves. Even though no resource transfers to squatters would then be required for formalization, the government must play an active role by offering land services. A dysfunctional government might fail to do so, blocking what would otherwise be a frictionless transition out of a squatter equilibrium.

${ }^{12}$ This difficulty could perhaps be addressed by a reduction in $h$, but the $t$ associated with minimum possible servicing expenditure could still be larger than formal households are willing to pay. It should also be noted that a more complex analysis would acknowledge the links between the spatial extent of a city's infrastructure network, the development of land, and squatting. In a situation where public resources for infrastructure provision are constrained, landowners who can successfully lobby the local government to get their land serviced would make it available for formal development, whereas those who are unsuccessful would keep the land undeveloped, encouraging squatting. Since landlord efforts in lobbying for infrastructure provision depend on the price of formal land, and since that price is affected by the squeezing effect from squatting, this more complex model would yield results comparable to those obtained using the current approach. 
${ }^{13}$ It can be shown that the second-order condition for choice of $A$ conditional on $N_{s}$ is satisfied under the example. The second total derivative of utility with respect to $A$, holding $N_{s}$ fixed, is globally negative.

${ }^{14}$ Note that this sequence is the reverse of the two-stage sequence discussed earlier in deriving the second-order conditions (choice of $N_{s}$ conditional on $A$ followed by choice of $A$ ).

${ }^{15}$ Figure 1's curve relating squatter utility to $N_{s}$ must have a local maximum at $N_{s}^{*}$ given satisfaction of the second-order conditions for the controlled-migration case.

${ }^{16}$ These expressions are given by $\Phi=(1-2 \alpha) \alpha y_{s} y_{f} \bar{N}_{f} /[2(1-\alpha) k \bar{L}]$ and $\Omega=\alpha^{2} y_{s} y_{f} \bar{N}_{f} /[(1-$ $\alpha) k \bar{L}]$. 